\title{
STRUCTURAL ANALYSIS OF LINKAGE MECHANISMS OF HYDRAULIC MANIPULATORS
}

\author{
M.A. Piskunov \\ piskunov_mp@list.ru \\ Petrozavodsk State University, Petrozavodsk, Republic of Karelia, \\ Russian Federation
}

Abstract
The structural schemes of hydraulic manipulators Hydraulic manipulator, structural
used in the roundwood handling operations are analysis, Assur group, roundwood
presented. The seventeen schemes of manipulators
are considered. The characteristic technological
processes are identified, the nominal motions of the
attachment mounted on the manipulator are de-
scribed and the structure of the manipulator used in
each process is considered. The variety of structures
of linkage mechanisms in manipulators is associat-
ed both with the accumulation of Assur groups and
with the increase in the Assur group class. Mecha-
nisms with the number of Assur groups up to 4 are
used. Assur groups of 2 nd and 3rd classes are main-
ly found in the mechanisms. Adding the degree of
freedom to the manipulator is accompanied by
emerging of an additional kinematic chain in the
structure. The structures studied are divided into
two groups: the first covers the structures in which
the input links are attached to the column; the sec-
ond consists of structures with internal inputs.
Variants of additional classification features are
proposed for structures with internal inputs. The
known provisions of structural analysis as a whole
allow the analysis to be performed if the internal
input is separated out as an individual input link.
Otherwise, it is necessary to correct the approaches
to the structural analysis of mechanisms having Received 02.04 .2018
internal input links

Studies in the field of searching for new and improving traditional methods of analysis and synthesis of the various mechanisms structure continues to be an important part of machine science and theory of mechanisms.

The main tasks of these studies remain the creation of formalized theoretical laws describing the structure of various mechanisms and their 
families, and the synthesis of certain new mechanism schemes by these laws based on certain specified conditions, with the aim of using them in solving practical problems.

The methods and approaches proposed by Russian scientists P.L. Chebyshev and L.V. Assur and further developed and systematized in the works of academician I.I. Artobolevsky are widely known and studied in universities as the classical foundations of structural analysis and synthesis of mechanisms. The method of synthesis proposed by German scientist M.F. Grubler, and the G.G. Baranov method are known and widely referred to in the scientific literature. A brief description of these methods is given in [1]. Other authors who have contributed to the development of structural synthesis are noted in $[2,3]$.

Studies in the field of analysis and synthesis of the mechanism structures is reflected in the works of professor E.E. Peysakh and professor L.T. Dvornikov, who, in particular, continued to work towards the development and application of methods for the synthesis of flat kinematic chains structures. The results of generating various structures are reflected, for example, in $[4,5]$, where the synthesized schemes of flat eight-link hinge mechanisms with one degree of freedom are presented, the synthesis of eight-link Assur groups based on the G.G. Baranov method is showed in [6], and a brief review of the state of research in the field of synthesis of flat hinge mechanisms was presented in [7].

The works of professor V.I. Pozhbelko are devoted to the theory of structure and directed analysis and synthesis of mechanisms, for example, a study in which the author solves the problem of directed structural synthesis of optimal mechanical systems is presented in [8], and the atlas of synthesized structures of eight-link single degree of freedom mechanisms is presented in [9].

The paper [10] presents an excursion into the historical domain and a rather detailed analysis of the state of the issue; the lines of research on which it is necessary to focus in the field of structural synthesis of mechanisms are touched upon.

The relevance and importance of research on the issues of synthesis is also confirmed by the discussion opened up on the pages of the "Theory of Mechanisms and Machines" magazine (for example [11, 12]) between scientists who have devoted numerous publications to structural synthesis.

Despite the fact that issues of synthesis of all possible structures of flat linkage mechanisms with one degree of freedom are not fixed, the practice pushes for the expansion of exploratory research related to the synthesis of flat linkage mechanisms structures in the direction of considering such structures with several degrees of freedom. 
Just as in his time professor P.L. Chebyshev addressed the issues of the mechanisms structure based on the experience with the Watt mechanisms ([3] with original sources $[13,14])$, so in the current period of time the practice "highlights" the tasks that need to be paid close attention.

The proliferation of hydraulic manipulators, with flat linkage mechanisms forming their structure, in various industries poses an urgent task to improve, adapt the already known approaches and methods, and develop new methods of analysis and synthesis for these mechanisms.

A special feature of hydraulic manipulator mechanisms, where hydraulic cylinders are used as motors, is that these mechanisms have a degree of freedom greater than one, and some of their input links (inputs) are attached not to the column, but to one of the moving links that are part of the overall mechanism structure.

A general overview and examples of such mechanisms used in various industries are presented in [15], where these mechanisms are defined as mechanisms with internal inputs. A confirmation of the relevance of the development and systematization of the theoretical foundations of the analysis and synthesis of such mechanisms is a direct reference in [16], where the author in this connection speaks of the need to introduce of additional classification of mechanisms into the theory of mechanisms.

Paying quite a lot of attention to theoretical aspects, they often obscure the influence of the technological process features on the mechanism structure, as well as the way these features give rise to one or another mechanism structure in the process of its design. Thus, if one considers full set of structures of all kinds, why exactly these or other structures (and not some others) find their application in practice?

This paper discusses the various structures of the linkage manipulator mechanisms used in the roundwood handling operations. The variety of technological processes in which these mechanisms were used led to the creation of a whole industry line of these mechanisms.

Work objective: to identify the features of the linkage mechanisms' structures that underlie the design of manipulators to grip, hold and move roundwood, to consider issues of the diversity of these mechanisms' structures and how the technological process in which these mechanisms are used is connected to the mechanism structure.

As the main method of studying the structure, we use the traditional method of analysis based on dividing the mechanism into Assur groups, as well as the results of the work of professors E.E. Peysakh and L.T. Dvornikov on the synthesis of flat linkage mechanisms' structures. 
Let's consider hydraulic manipulators designed to grip, hold and move roundwood (hereinafter referred to as objects) that differ in size (length, diameter), orientation and location in space (vertically positioned, horizontally positioned, single and grouped). We classify technological processes used in the current industry practice by type of nominal motions of the attachment, and for each technological process we consider the structure of the manipulator's linkage mechanism.

By nominal motions we mean motions, the minimum number of which is sufficient to fulfill the mechanism function in one cycle, i.e., motions associated with additional maneuvers of the attachment, with regrips of objects, with grouping of objects for their convenient grip are excluded from consideration.

Process 1. Lifting several lengthy objects from the ground surface and holding them, grouped in one bundle, while moving this pack to a distance up to $1 \mathrm{~km}$. One end of the bundle rises above the ground, the other is in contact with the ground surface. The gripper is used as the attachment. Nominal gripper motion is a single up/down movement, the gripper motion trajectory is an arc of a circle.

Process 2. The process is similar to process 1 , with the difference that the bundle is being enlarged due to its formation from bundles of a smaller volume. Nominal gripper motions are several up/down movements; the trajectory is a flat curve.

For process 1, the manipulator with the structure shown in Fig. 1, a (kinematic scheme without scale) is used. The manipulator has two degrees of freedom. The linkage mechanism is a four-link mechanism (moving links 1,2, 3 and column) with three turning kinematic pairs $(A, C, D)$ and one rectilinear pair $(B)$, links 1 and 2 are the hydraulic cylinder links, realizing the first degree of freedom. The gripper suspension assembly 4 includes three kinematic pairs $(E, F, G)$. The second degree of freedom, the rotation of the gripper, is carried out by the hydraulic motor and is realized by the kinematic pair $E$. Kinematic

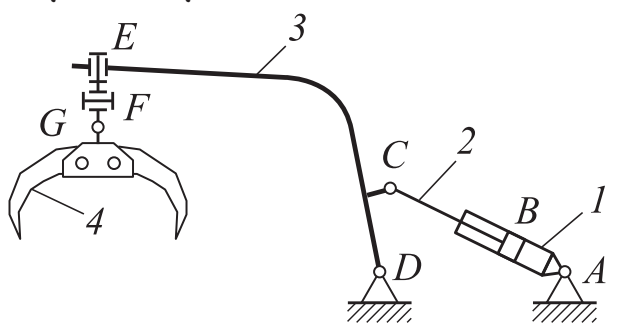

$a$

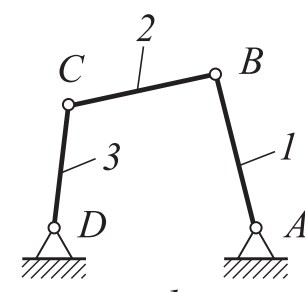

$b$

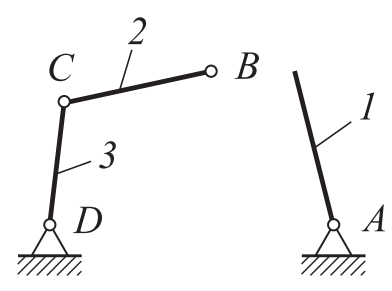

C

Fig. 1. Scheme of the manipulator for process 1:

$a$ is kinematic scheme; $b$ is structural diagram; $c$ is structural groups 
pairs $G$ and $F$ provide free swinging of the gripper while retaining the bundle, ensuring reduction of dynamic loads on link 3.

Having performed the conditional replacement of the rectilinear pair $B$ by the turning one, we present the structural diagram of the linkage mechanism (Fig. 1,b) and divide this scheme into Assur groups (Fig. 1, c). We obtain a wellknown structure consisting of a class I mechanism and one Assur group of class II (structure formula: I $\rightarrow$ II).

In process 2, compared with process 1 , the formation of double bundles requires an increase in the gripper maneuverability. In the diagram in Fig. 1 the gripper can move only along a certain arc of a circle. For process 2 , the mechanism structure should provide movement along different flat trajectories within a certain working area.

An additional hydraulic cylinder appears in the mechanism structure, providing the third degree of freedom for the manipulator (Fig. 2, a, links 4, 5). Another class I mechanism and another Assur class II group are added to the structure of the linkage mechanism (Fig. 2, b, c). The second Assur group (links 5, 6) is attached to the class I mechanism and the Assur class II group, formed by the links 2, 3, (Fig. 2,c). The formula for the mechanism structure is as follows:

$$
\begin{aligned}
& \mathrm{I}(1, \text { column }) \rightarrow \underset{\uparrow}{(2,3)} \\
& \mathrm{I}(4, \text { column }) \rightarrow \mathrm{II}(5,6)
\end{aligned}
$$

Besides the additional Assur group, a link, which is included in three kinematic pairs, appears in the mechanism structure - link 3 (Fig. 2, b, c); in accordance with the system of equations describing the mechanism structure from [5], the link included in the largest number of kinematic pairs is the base link. The greatest number of kinematic pairs into which a link is simultaneously included is denoted by $\tau$. For the mechanism in Fig. $2 \tau=3$ and in the structure of this mechanism there are two such links.

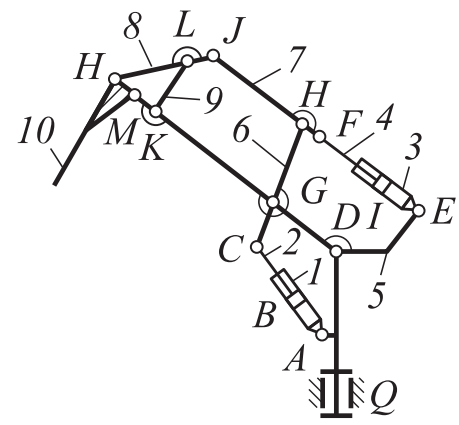

$d$

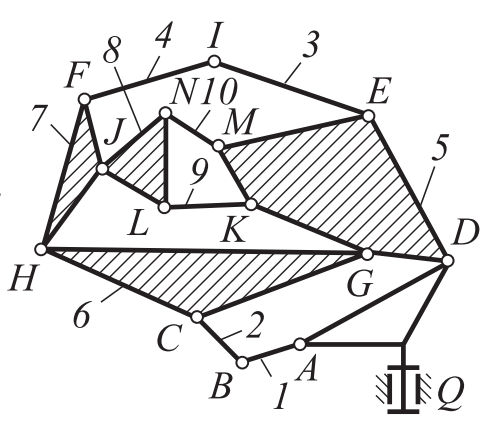

$e$

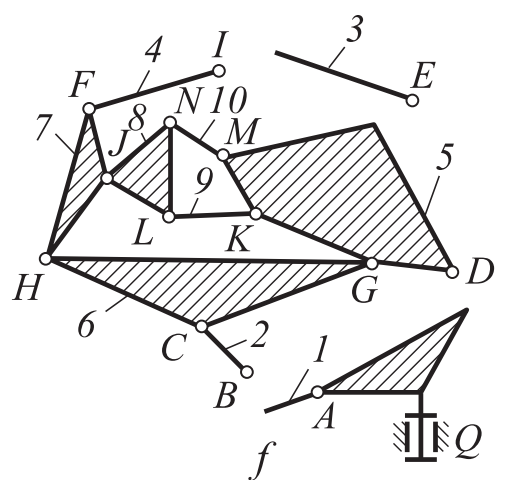

$f$

Fig. 2. Scheme of the manipulator for process 2:

$a$ is kinematic scheme; $b$ is structural diagram; $c$ is structural groups 
Process 3. Lifting a large bundle of objects out of the stack, holding, moving this bundle within the yard and unloading the bundle. Nominal gripper motion - single down/up movement. Gripping of objects is carried out from top of the stack.

In the mechanism structure, the suspension assembly changes, kinematic pairs allowing the gripper to rotate freely are removed, but one more degree of freedom is added, which is realized by another hydraulic cylinder (Fig. 3, $a$, links 7,8 ). The mechanism has four degrees of freedom, including the drive in the $M$ pair. Considering the general structural diagram (Fig. 3, b, c), we separate out in the mechanism three Assur class II groups, two class I mechanisms (links 4, 1) and one internal input - link 7. The Assur group, consisting of links 8 and 9 , is not attached to the column, but is attached to the moving link 6 . The formula for the mechanism structure is as follows:

$$
\begin{aligned}
& \mathrm{I}(1, \text { column }) \rightarrow \mathrm{II}(\underset{\uparrow}{(2,3)} \\
& \mathrm{I}(4, \text { column }) \rightarrow \mathrm{II}(5,6) \rightarrow \mathrm{I}(7) \rightarrow \mathrm{II}(8,9)
\end{aligned}
$$

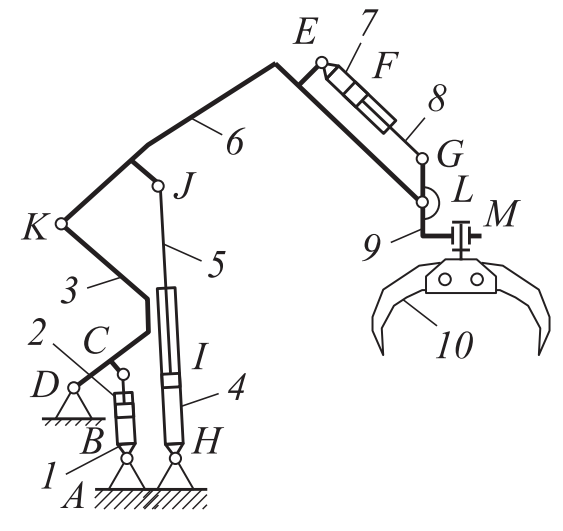

$a$

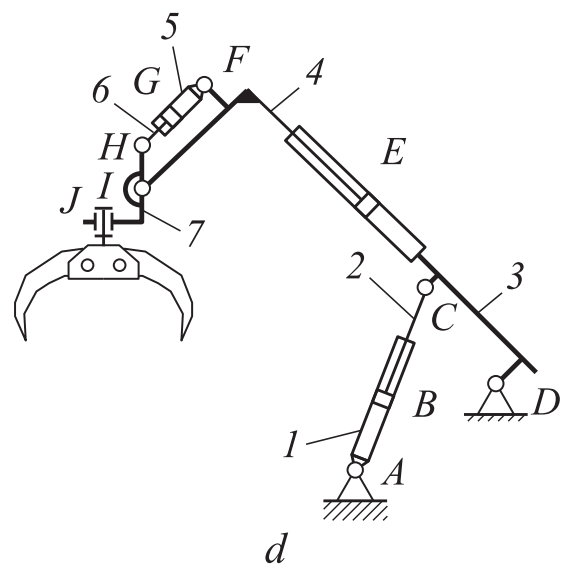

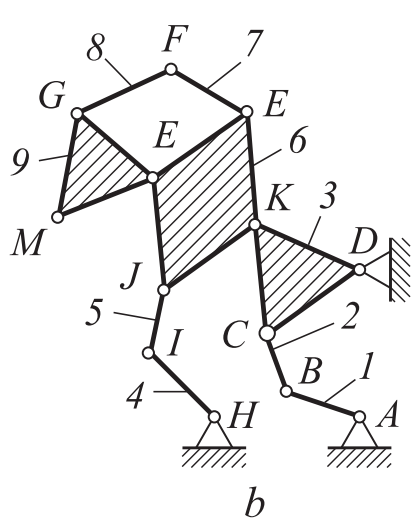
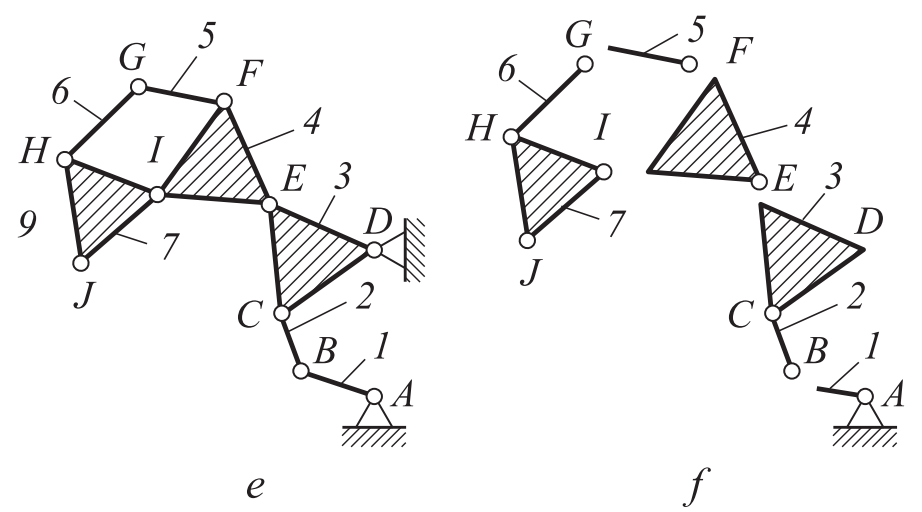

Fig. 3. Schemes of the manipulators for process 3:

$a, d$ are kinematic schemes; $b, e$ are structural diagrams; $c, f$ are structural groups 
A link, which is included in four kinematic pairs, appears in the mechanism structure - link 6 (Fig. 3) $\tau=4$. There is a combination of links in the mechanism structure, which is included in four and three kinematic pairs.

The modified mechanism structure for performing a similar process excludes the intermediate Assur group - links 5 and 6, instead of it an internal input link 4 is set (Fig. $3, d$ ). The structural diagram of this mechanism and the division of the scheme into groups are presented, respectively, in Fig. 3, $e, f$. The formula for the mechanism structure is as follows:

$$
\mathrm{I}(1, \text { column }) \rightarrow \mathrm{II}(2,3) \rightarrow \mathrm{I}(4) \rightarrow \mathrm{I}(5) \rightarrow \mathrm{II}(6,7)
$$

Process 4. Lifting a large package (bundle) of objects from the stack, holding, moving this bundle within the yard and unloading the bundle. Nominal gripping motions - a single up/down movement, a single rotation of the gripper around an axis parallel to the transverse axis of the machine passing through the lower hinge of the gripper. Gripping of objects is carried out both from top and from the side of the stack.

The mechanism structure (Fig. 4, $a$ ) includes two class I mechanisms and three Assur class II groups (Fig. 4, b, c). The change in the structure compared to the above schemes is that the third Assur group (links 7, 8, Fig. 4,c) is attached to links 6, 3 (Fig. 4, c), which in turn are links of two different Assur groups. The formula for the mechanism structure is the following:

$$
\begin{aligned}
& \mathrm{I}(1, \text { column }) \rightarrow \underset{\downarrow}{\mathrm{II}} \underset{\downarrow}{(2,3)} \rightarrow \underset{\uparrow}{\mathrm{II}} \underset{\uparrow}{(7,8)} \\
& \text { I }(4, \text { column } \rightarrow \text { II }(5,6) \rightarrow \uparrow
\end{aligned}
$$

The alternative mechanism structure (Fig. $4, d$ ) used in process 4 consists of two class I mechanisms (links 1 and 4), two Assur class II groups (links 2, 3 and 5,6) and Assur class III group - links 7-10 (Fig. 4, e, f).

A link, that is included in five kinematic pairs, appears in the mechanism structure - (Fig. $4, e) \tau=5$. There is a combination of links in the structure included in five and three kinematic pairs. This mechanism mostly works with the gripping of objects from the side of the stack. The formula for the mechanism structure is as follows:

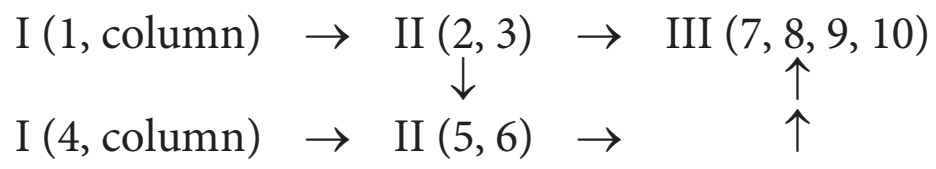

Process 5. Gripping, lifting, moving and unloading single objects into the cargo compartment, where such objects are distributed over a certain area within the limits of the manipulator in-out. Nominal motions - repeated 

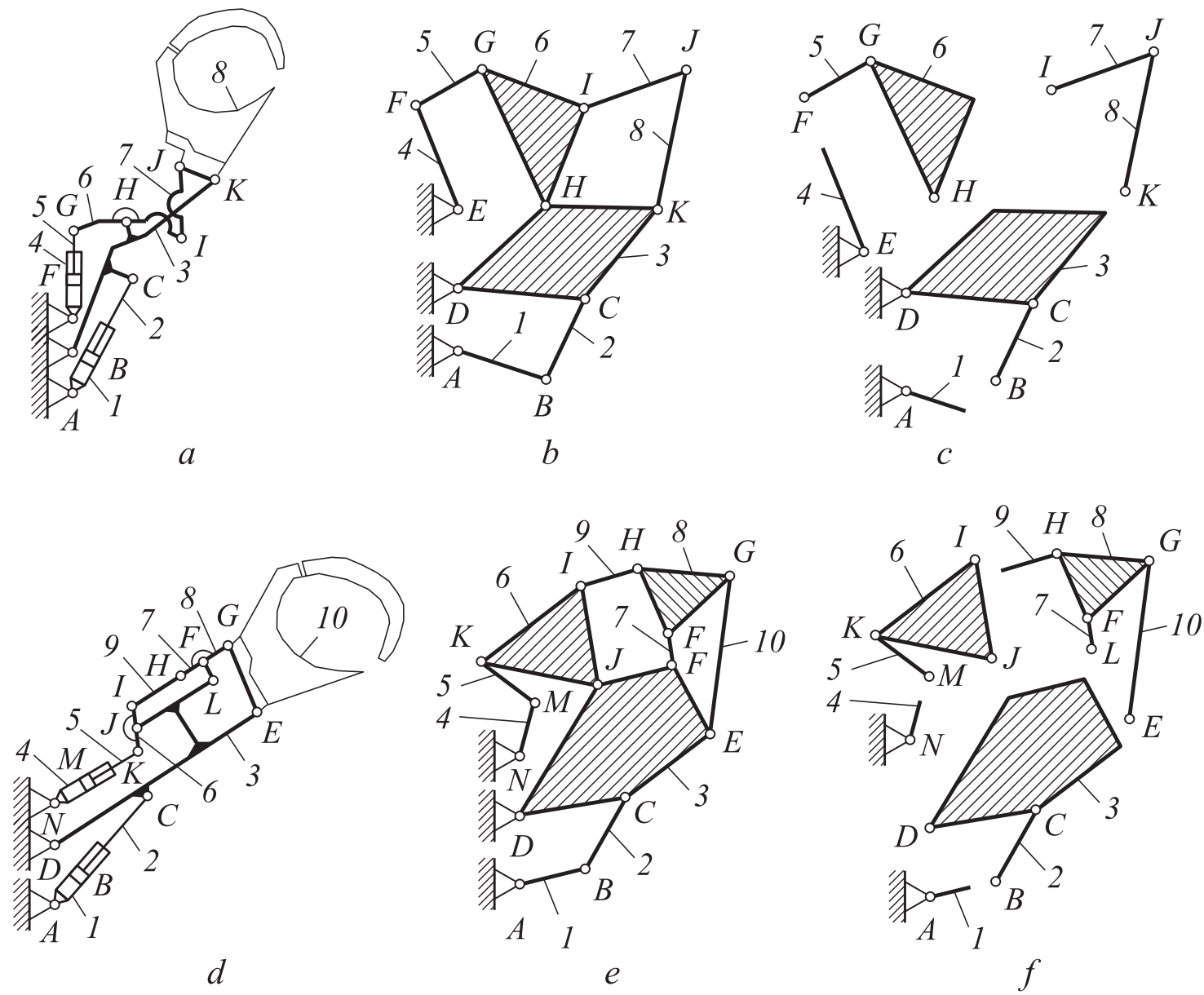

Fig. 4. Schemes of the manipulators for process 4:

$a, d$ are kinematic schemes; $b, e$ are structural diagrams; $c, f$ are structural groups

up/down movements, rotations of the whole mechanism around the vertical axis, multiple changes of the manipulator in-out. Several mechanisms structures are used in this process.

The mechanism structure (Fig. 5, a) includes the class I mechanism, to which the Assur class II group is attached, and the link 4 - an internal input (Fig. 5, b,c), and another Assur class II group (links 5,6) are attached to this group. Link 3 in this structure is a base link with $\tau=4$.

In addition, in the manipulator structure there is a kinematic pair $Q$, which realizes the rotation of the whole mechanism around the vertical axis. Additional mobility of the manipulator is provided by a telescopic extension - link 7 . There can be 1 or 2 extenders. The suspension assembly (pair $K$ ) ensures the free swing of the attachment. The formula for the mechanism structure is as follows:

$$
\begin{array}{cccc}
\mathrm{I}(1, \text { column }) & \rightarrow \quad \mathrm{II}(2,3) & \rightarrow & \downarrow \\
& \downarrow & & \downarrow \\
& \mathrm{I}(4) & \rightarrow & \text { II }(5,6)
\end{array}
$$




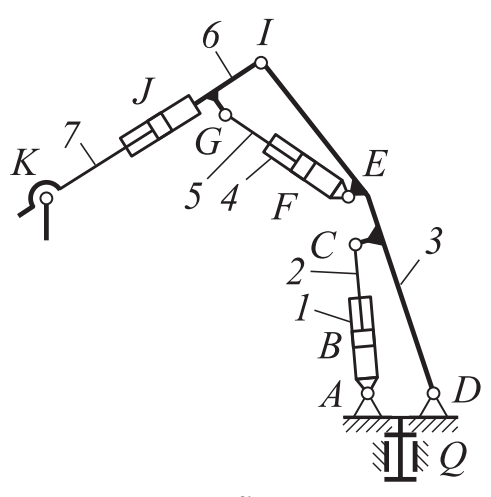

$a$

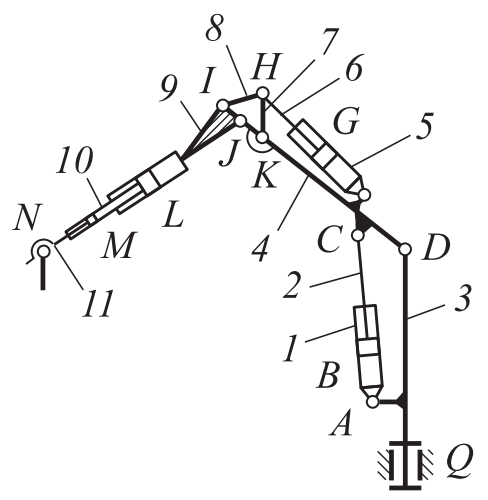

$d$

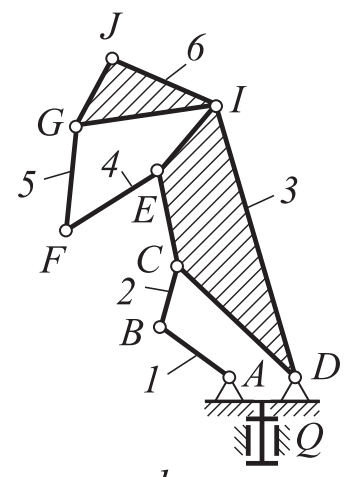

$b$

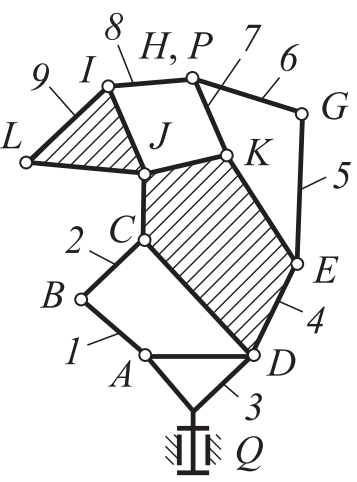

$e$

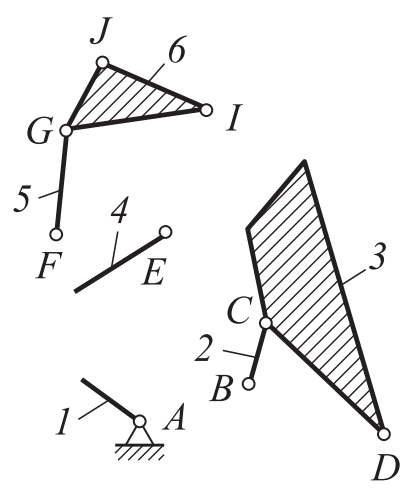

$c$

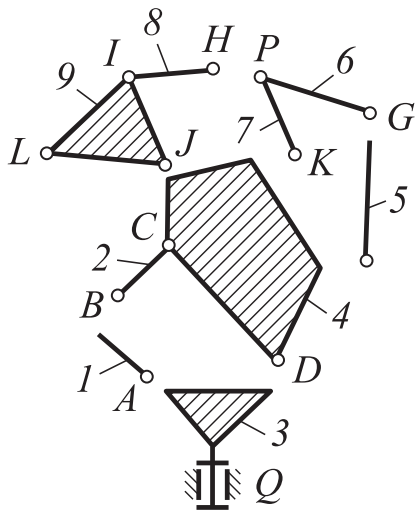

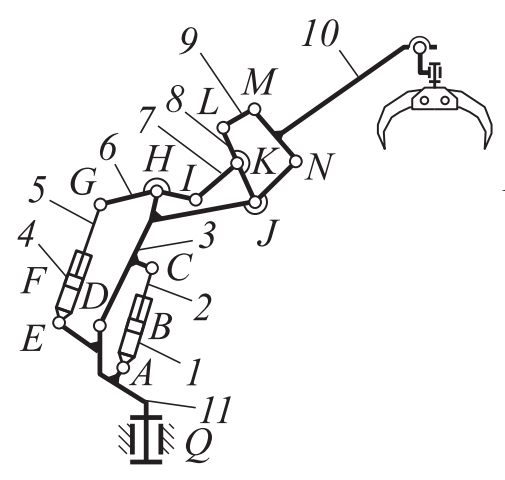

$g$

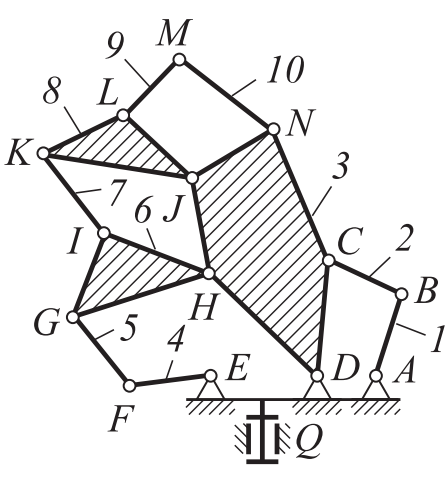

$h$

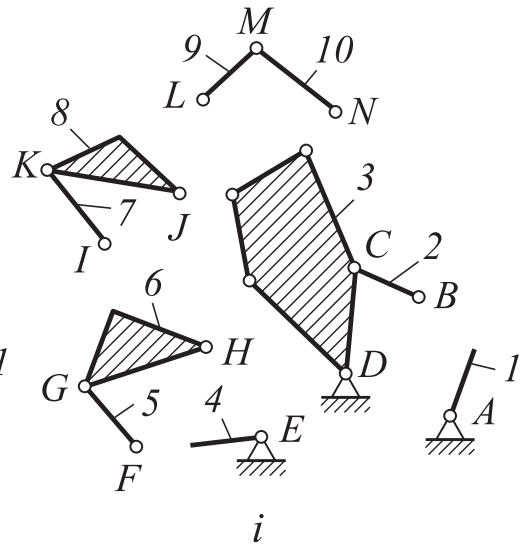

Fig. 5. Schemes of the manipulators for process 5 :

$a, d, g$ are kinematic schemes; $b, e, h$ are structural diagrams; $c, f, i$ are structural groups

The mechanism structure (Fig. 5, $d$ ) also includes the class I mechanism (link 1), the internal input (link 5), two Assur class II groups (links 2, 4 and 6,7 ) and another class II group ( links 8,9 ), which is attached to the previous groups (Fig. 5, e,f).

A complex hinge $H$ and a base link - link 4 with five kinematic pairs $(\tau=5)$ appear in the mechanism structure. The formula for the mechanism structure is as follows: 


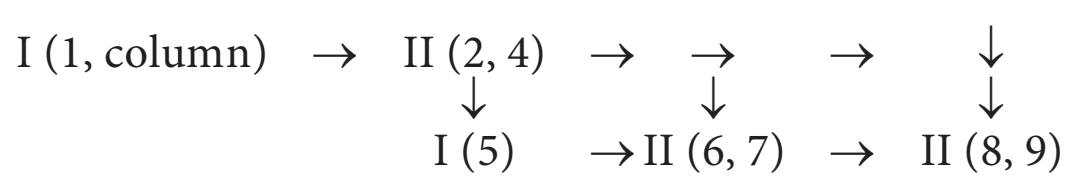

The structure (Fig. 5, $g$ ) is used in the manipulator, which can work both in process 5 and 4 , but in process 4 it can handle bundles of much smaller dimensions. A feature of the structure of this mechanism is the presence of four Assur groups (Fig. 5, $h, i$ ). All groups are Assur II class ones. The formula for the mechanism structure is as follows:

$$
\begin{aligned}
& \mathrm{I}(1, \text { column }) \rightarrow \underset{\downarrow}{\mathrm{II}(2,3)} \rightarrow \underset{\downarrow}{\rightarrow} \rightarrow \underset{\downarrow}{\downarrow} \\
& \text { I }(4, \text { column }) \rightarrow \text { II }(5,6) \rightarrow \text { II }(7,8) \rightarrow \text { II }(9,10)
\end{aligned}
$$

Process 6. Gripping a single object located in a vertical position, moving an object in a vertical position within the manipulator in-out, putting the object into a horizontal position.

Nominal motions - movement of the attachment along different trajectories in the horizontal plane; rotation of the attachment around an axis parallel to the transverse axis of the machine passing through the lower hinge of the attachment.

The manipulator used for this scheme implements rectilinear trajectories of the attachment movement in a horizontal plane. The manipulator diagram is shown in Fig. 6, $a$ (the kinematic pair, which allows the manipulator to rotate about the vertical axis, is not indicated).

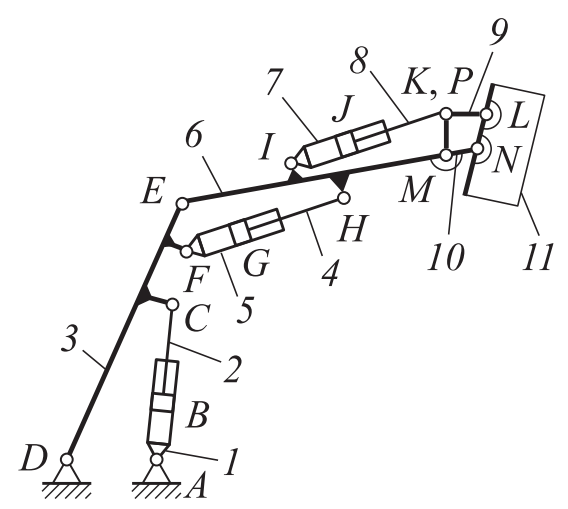

$a$

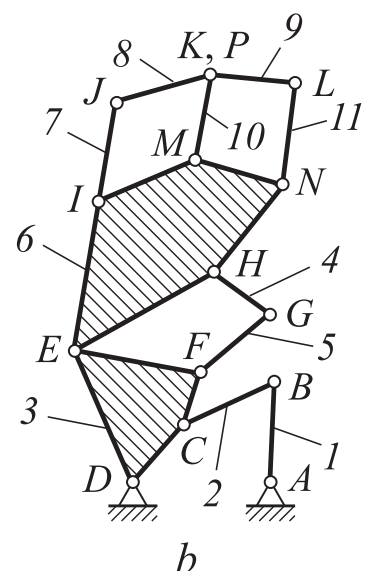

$b$

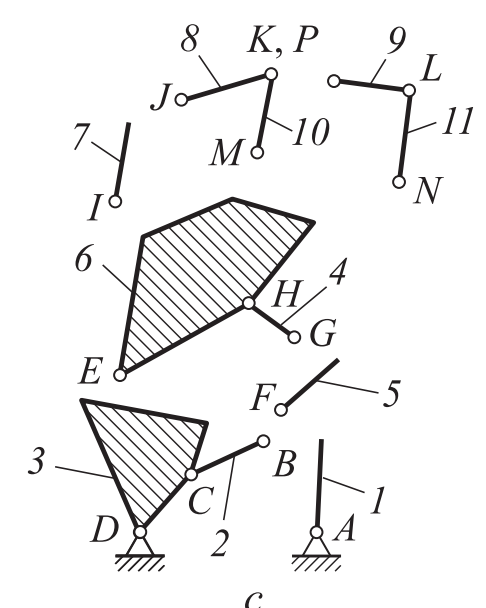

$c$

Fig. 6. Scheme of the manipulator for process 6:

$a$ is kinematic scheme; $b$ is structural diagram; $c$ is structural groups

The manipulator structure includes the class I mechanism (link 1 and column); two internal inputs - links 5 and 7 , and 4 Assur II class groups (pairs of links: 2 and 3; 4 and 6; 8 and 10; 9 and 11, Fig. 6, b,c). A combination of links 
included in four and five kinematic pairs appears in the mechanism structure. The structure formula is as follows:

$$
\begin{aligned}
& \mathrm{I}(1, \text { column }) \underset{\downarrow}{\mathrm{II}(2,3)} \rightarrow \underset{\uparrow}{\mathrm{II}(4,6)} \rightarrow \underset{\downarrow}{\mathrm{I}} \rightarrow \underset{\downarrow}{\rightarrow} \rightarrow \underset{\downarrow}{\downarrow} \rightarrow \underset{\downarrow}{\downarrow} \\
& \mathrm{I}(5) \quad \rightarrow \quad \uparrow \quad \downarrow \quad \rightarrow \quad \text { I (7) } \rightarrow \quad \text { II }(8,10) \rightarrow \text { II }(9,11)
\end{aligned}
$$

Process 7. Gripping single object or small groups of objects located horizontally, moving objects along a vertical straight line, unloading objects. Nominal motions - up/down movements, rotation of the attachment. The movement of objects is carried out within the yard.

The manipulator scheme is shown in Fig. 7, a. This structure is characterized by the presence of a pantograph mechanism - the quadrangles DEFG and GHJM (Fig. 7, a), which allows to maintain the linearity of the attachment trajectory during lifting and lowering of the manipulator in a certain segment of the movement.

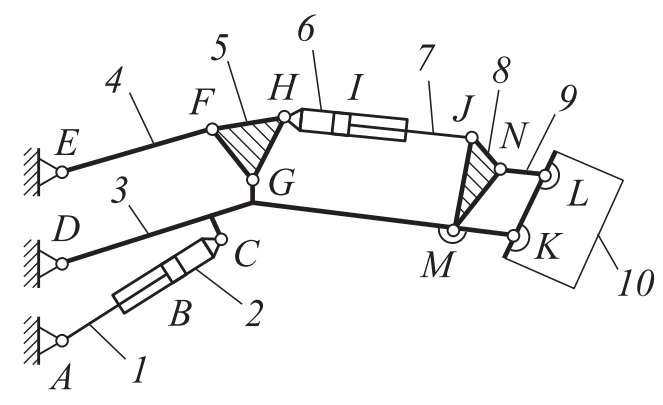

$a$

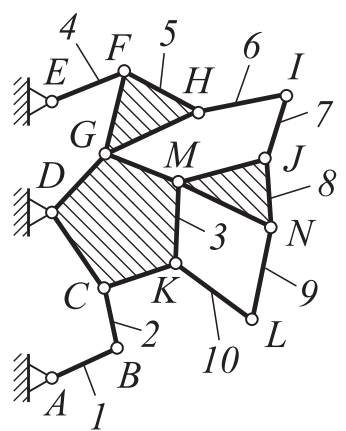

$b$

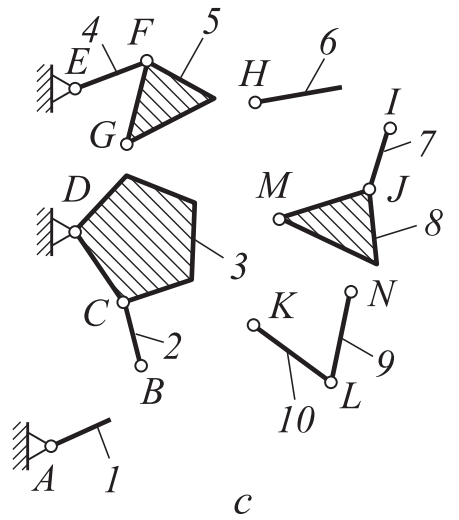

$c$

Fig. 7. Scheme of the manipulator for process 6 :

$a$ is kinematic scheme; $b$ is structural diagram; $c$ is structural groups

The manipulator structure includes the class I mechanism (link 1 and column); one internal input - link 6 and 4 Assur Class II groups (pairs of links: 2 and $3 ; 4$ and 5; 7 and $8 ; 9$ and 10, Fig. 7, b, c). There is a modification of the structure when one link is used instead of a hydraulic cylinder with two links 6 and 7.

Process 8. Gripping single objects located vertically; putting (tilting) the object in a horizontal position; moving an object in a horizontal plane. Nominal motions - movement of the attachment along different trajectories mainly in the same horizontal plane. There are various options for the structure of the mechanism used in this process. The difference of the schemes is associated with the location of the drive cylinders.

Scheme No. 1 is the basic scheme (Fig. 8, a) includes three Assur groups two of Class II, one of Class III, one internal input (link 6, Figure 8, b,c). There 

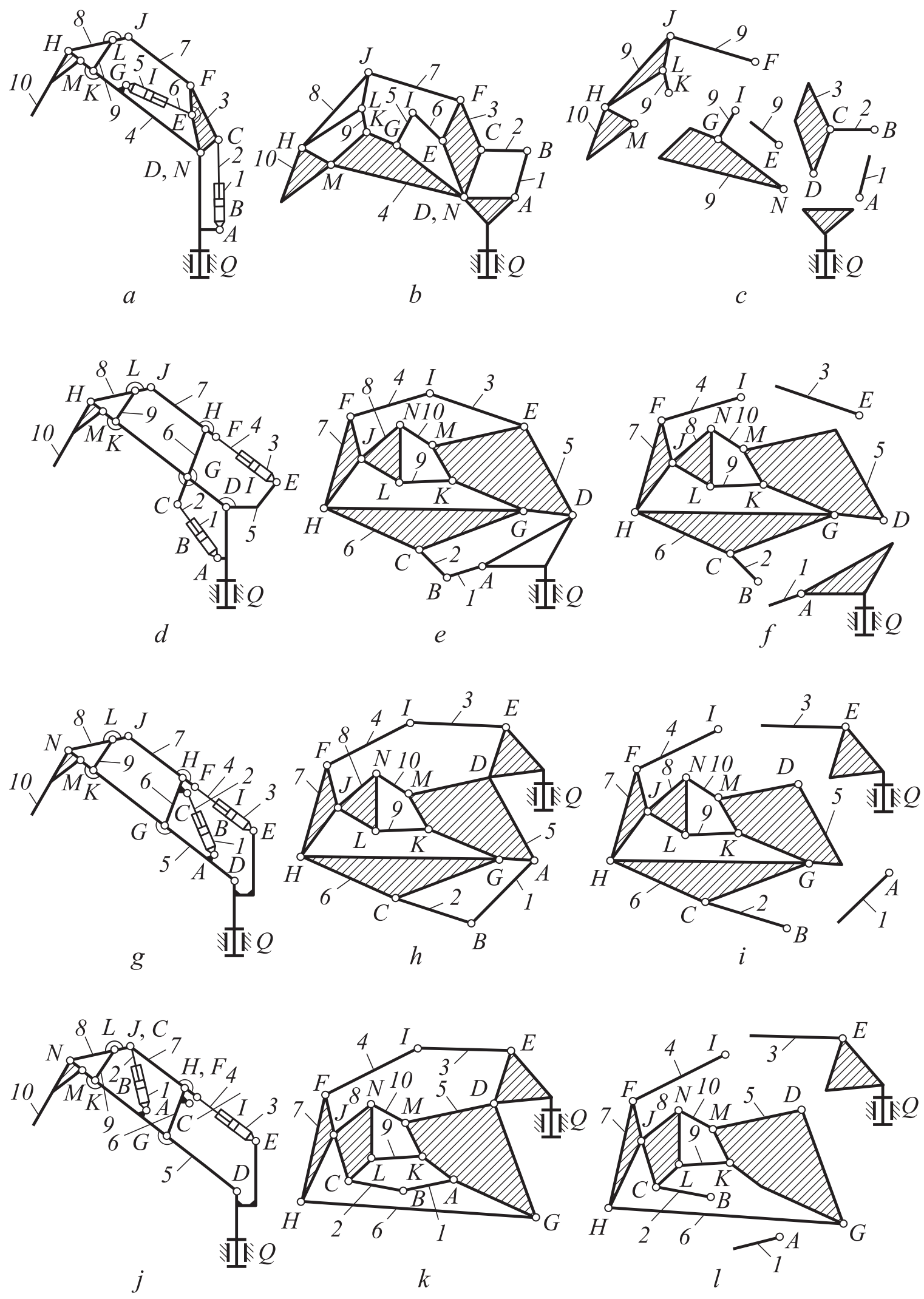

Fig. 8 (part 1). Schemes of the manipulators for process 8 :

$a, d, g, j$ are kinematic schemes; $b, e, h, k$ are structural diagrams;

$c, f, i, l$ are structural groups 

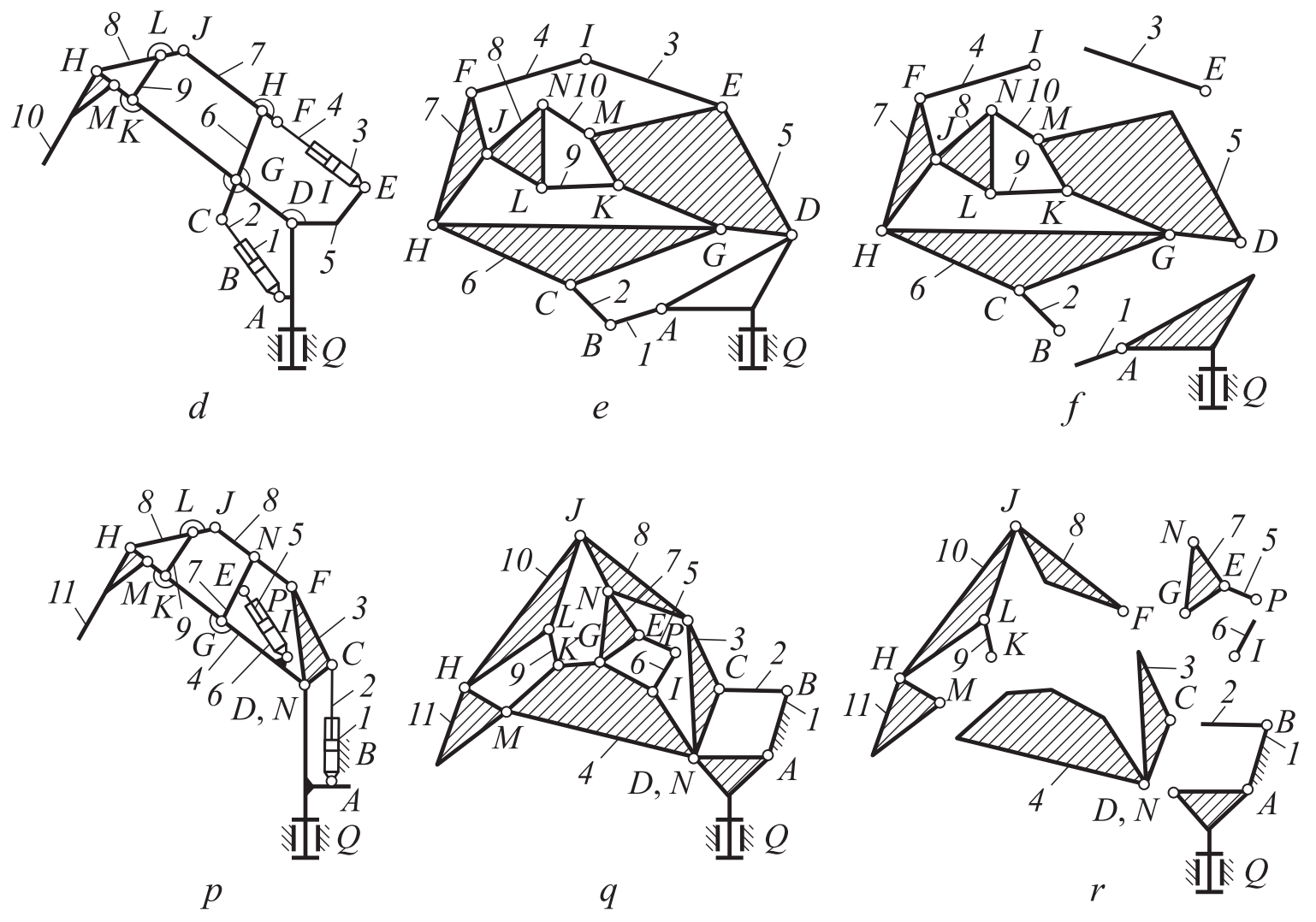

Fig. 8 (part 2). Schemes of the manipulators for process 8: $m, p$ are kinematic schemes; $n, q$ are structural diagrams; $o, r$ are structural groups

is one complex hinge $(D, N)$. The base link with five kinematic pairs and a combination of links included in three, four, and five kinematic pairs. If link 6 is not involved (kinematic pair $I$ is absent), then this scheme can be considered as a mechanism without internal inputs and with three Assur groups (two groups of class II and one of class III). The formula for the mechanism structure is as follows:

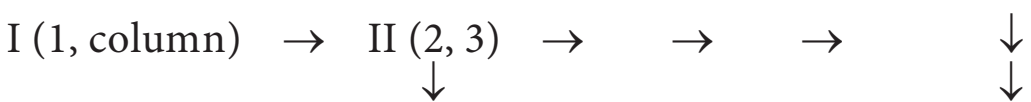

$$
\begin{aligned}
& \mathrm{I}(6) \rightarrow \operatorname{II}(5,4) \rightarrow \operatorname{III}(7,8,9,10)
\end{aligned}
$$

Scheme No. 2. The mechanism structure (Fig. 8, $d$ ) includes the class I mechanism (link 1), the internal input (link 3); if these two mechanisms are removed, the eight-link Assur group remains (Fig. 8, e, f). According to the classification given in [2], a similar group received the number 8GA109.

If we fix links 3 and 4 and exclude their movement relative to each other, then in this case the combination of link 2 and all other links is a kinematic chain with zero degree of freedom, that is, with an unused internal input, we 
get a structure with one Assur II class group in which the first link is link 2, the second link is a truss consisting of links 3-10.

A mechanism similar in structure is shown in Fig. $8, g, h, i$. The difference is the location of one of the hydraulic cylinders (links 1,2$)$.

Scheme No. 3. The mechanism structure (Fig. 8, j) includes the class I mechanism (link 3), the internal input (link 1) and the eight-link Assur group (Fig. 8, $k, l$ ); according to [2], the group received the designation 8GA146.

Scheme No. 4. The mechanism structure (Fig. 8, $m$ ) consists of similar structural elements, but the eight-link Assur group (structure diagram, Fig. 8, $n$, Assur groups, Fig. 8,o) is of different type and is indicated in [2] as 8GA149.

Scheme No. 5. In the mechanism structure (Fig. 8, $p, q$ ) link 1 is motionless (kinematic pair $A$ is absent), and the hydraulic cylinder (links 1 and 2) is positioned so that link 2 can freely make movements.

A complex hinge (kinematic pairs $D, N$ ) allows links 4 and 3 to rotate both relative to each other and relative to the column.

Let us single out links 1 and 2 as a class I mechanism (Fig. 8, r), where link 1 is the column and the internal input is link 6 . We divide the remaining kinematic chain into groups: links 3 and 4; links 7, 5 (class II Assur group); links 8-11 (class III Assur group). If we assume that link 4 is attached to the column, and link 3 - to link 4, then the kinematic chain without links 5-7, that form the internal chain, corresponds to the chain belonging to the structure of the eight-link mechanism, designated as $8 \mathrm{M} 90$ in [4].

The structure analysis of the linkage mechanisms of manipulators for roundwood has shown that the following are the classification attributes: a group class, a combination of links included in different number of kinematic pairs; the number of internal inputs; the number of primary mechanisms. Also, as a classification attribute, we select the number of Assur groups before the first internal input; the number of Assur groups between internal inputs and the number of Assur groups after the last internal input.

The development of the mechanism structures is associated both with an increase in the number of Assur groups, and with a change in the group class. For most mechanisms, an increase in the degree of freedom is accompanied by the emergence of an additional kinematic chain in the structure, rather than a separate kinematic pair.

It is advisable to divide the manipulator structures into two groups: the first is the mechanisms in which the input links are attached only to the column; the second is mechanisms with internal inputs, where some of the input links are attached to other moving links. 
Using the known methods of structural analysis, it is possible to disassemble the structure of the manipulator mechanisms; however, additional provisions are required, for example, the rules for the correct separating out the internal inputs; correct analysis of the structure of nested kinematic chains - chains that go from the internal input to the output link; in what cases to consider nested chains as trusses.

The considered mechanisms are controlled by a human operator. To control the hydraulic cylinders the control levers (joysticks) are used. One movement of the lever causes the input link to move in one direction with certain speeds and accelerations. To get into the desired motion trajectory of the attachment, the operator must simultaneously carry out several movements with the control levers. Such control generates significant deviations from some optimal kinematic parameters of the attachment motion and, as a result, leads to losses: reduced performance, increased fuel consumption; additional dynamic loads on the structure.

The imperfection of the control system can be somewhat compensated by the mechanism structure, for example, in some segments of the movement, instead of acting on two levers, the operator moves only one lever due to the matched mechanism structure of the. For example, in the mechanisms for process 8 , where in the basic scheme No. 1 a structure with an internal input is used, after which two groups of II and III classes are attached, or a mechanism for process 7, where a pantograph is used to keep the straightness of the attachment motion.

Conclusions. The variety of hydraulic manipulator structures, used only within one particular industry, already shows the relevance and practical demand of theoretical work on the creation of formalized laws for the development of structures of these mechanisms. Such work will undoubtedly be demanded by designers of hydraulic manipulators, especially in light of the emerging trend of transition to the development of industrial manipulation robotic systems in many industries.

Translated by K. Zykova

\section{REFERENCES}

[1] Gudimova L.N., Dvornikov L.T. Analysis of scientific researches in area of synthesis of structure of flat kinematics chains. Fundamental'nye issledovaniya [Fundamental Research], 2013, no. 10-11, pp. 2410-2417 (in Russ.).

[2] Peysakh E.E. Catalog of eight-link planar Assur groups. Teoriya mekhanizmov i mashin [Theory of Mechanisms and Machines], 2007, vol. 5, no. 2, pp. 15-27 (in Russ.). 
[3] Dvornikov L.T. Problemy mekhaniki sovremennykh mashin [Current state of mechanism structure theory]. Mat. V mezhdunar. konf. T. 1 [Proc. V Int. Conf. Vol. 1]. Ulan-Ude, Izd-vo VSGUTU Publ., 2012, pp. 40-43 (in Russ.).

[4] Peysakh E.E. Atlas of type diagrams of eight-link planar linkages. Teoriya mekhanizmov i mashin [Theory of Mechanisms and Machines], 2006, vol. 4, no. 1, pp. 3-17 (in Russ.).

[5] Dvornikov L.T. Structural analysis of mechanisms. Teoriya mekhanizmov $i$ mashin [Theory of Mechanisms and Machines], 2004, vol. 2, no. 2, pp. 3-17 (in Russ.).

[6] Dvornikov L.T., Gudimova L.N. The analysis of a method of the professor Baranov G.G. on search eight-links flat turning groups of Assur. Mashinostroenie, 2006, no. 16, pp. 27-40 (in Russ.).

[7] Peysakh E.E. Structural analysis of planar jointed mechanisms: Current state and problems. J. Mach. Manuf. Reliab., 2008, vol. 37, no. 3, pp. 207-212.

DOI: $10.3103 /$ S1052618808030011

[8] Pozhbelko V.I. Universal theory of structures, general properties and algorithms for the directed synthesis and analysis of statically determinate mechanical systems. Part 1. Optimal structure of mechanisms and trusses. Izvestiya vysshikh uchebnykh zavedeniy. Mashinostroenie [Proceedings of Higher Educational Institutions. Machine Building], 2014, no. 1, pp. 24-35 (in Russ.). DOI: 10.18698/0536-1044-2014-1-24-35

[9] Pozhbelko V.I. A universal method for the topological synthesis of many-loop structures and atlas of eight-link kinematic chains and its invariants. Teoriya mekhanizmov $i$ mashin [Theory of Mechanisms and Machines], 2014, vol. 12, no. 2, pp. 50-65 (in Russ.).

[10] Dvornikov L.T. [The starting point and methodical foundations of structural synthesis of the complete variety of machine kinematic chains]. Mat. 19 nauch-prakt. konf. po problemam mekhaniki i mashinostroeniya [Proc. 19 Sc.-Pract. Conf. on Problems of Mechanics and Machine Engineering]. Novokuznetsk, Sib. gos. industr. un-t Publ., 2009, pp. 5-18 (in Russ.).

[11] Peysakh E.E. To discussion on the problem of structural synthesis of planar linkages. Teoriya mekhanizmov i mashin [Theory of Mechanisms and Machines], 2006, vol. 4, no. 1, pp. 49-54 (in Russ.).

[12] Dvornikov L.T. On principal incorrectness in studies on mechanisms structure of Pozhbelko V.I. Teoriya mekhanizmov $i$ mashin [Theory of Mechanisms and Machines], 2016, vol. 14, no. 3, pp. 145-166 (in Russ.).

[13] Krylov A.N. Pafnutiy L'vovich Chebyshev. Biograficheskiy ocherk [Pafnutiy Lvovich Chebyshev. Biographic essay]. Moscow, Leningrad, Izd-vo AN SSSR Publ., 1944.

[14] Chebyshev P.L. O parallelogrammakh. Polnoe sobranie sochineniy Chebysheva P.L. T. IV. Teoriya mekhanizmov [On parallelograms. Complete set of works by Chebyshev P.L. Vol. IV. Mechanisms theory]. Mocow, Leningrad, Izd-vo AN SSSR Publ., 1948.

[15] Semenov Yu.A. Application of machines and mechanisms with internal inputs. Teoriya mekhanizmov i mashin [Theory of Mechanisms and Machines], 2003, vol. 1, no. 1, pp. 30-49 (in Russ.). 
[16] Ashcheulov A.V. When mechanisms with internal inputs which are simple for theory of machines and mechanisms become complex for design. Teoriya mekhanizmov i mashin [Theory of Mechanisms and Machines], 2003, vol. 1, no. 2, pp. 76-78 (in Russ.).

Piskunov M.A. - Cand. Sc. (Eng.), Assoc. Professor, Department of General Technical Subjects, Institute of Forestry, Mining and Construction Sciences, Petrozavodsk State University (Lenina prospekt 33, Petrozavodsk, Republic of Karelia, 185910 Russian Federation).

\section{Please cite this article as:}

Piskunov M.A. Structural analysis of linkage mechanisms of hydraulic manipulators. Herald of the Bauman Moscow State Technical University, Series Mechanical Engineering, 2019, no. 5, pp. 74-90. DOI: 10.18698/0236-3941-2019-5-74-90

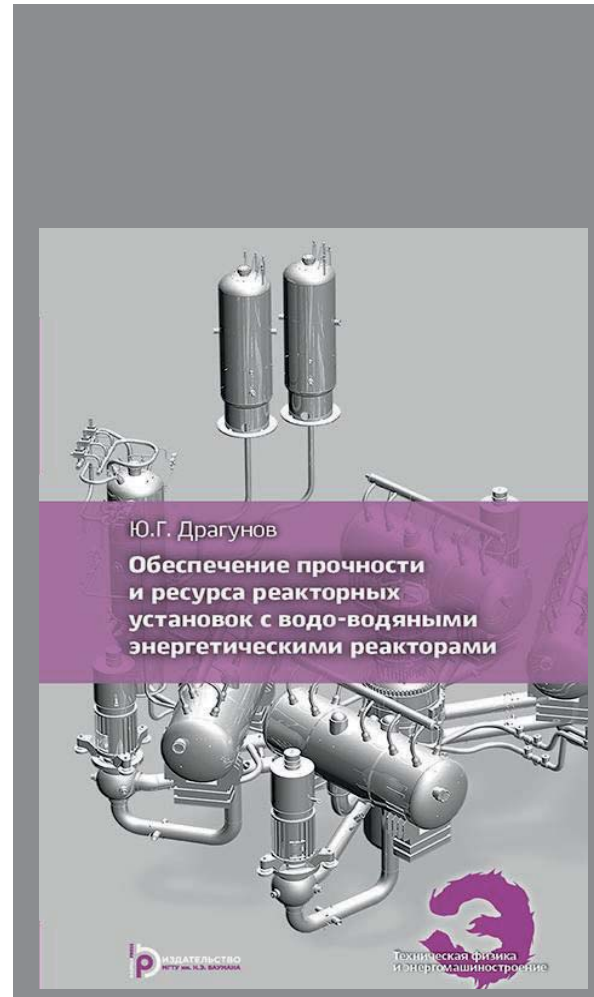

\section{В Издательстве МГТУ им. Н.Э. Баумана вышло в свет учебное пособие автора \\ Ю.Г. Драгунова \\ «Обеспечение прочности и ресурса реакторных установок с водо-водяными энергетическими реакторами»}

Изложены подходы к обоснованию безопасности реакторных установок с водо-водяными энергетическими реакторами, в частности прочности оборудования, с учетом нагрузок и изменений свойств материалов в условиях нормальной эксплуатации и при авариях. Рассмотрены вопросы управления ресурсом критических элементов оборудования реакторных установок с водоводяными энергетическими реакторами.

Пособие адресовано студентам специальности «Ядерные реакторы и материалы», может быть полезно для студентов и аспирантов, обучающихся по направлению подготовки «Ядерная энер гетика и технологии», а также специалистов, работающих в области создания оборудования для ядерной индустрии.

По вопросам приобретения обращайтесь:

105005, Москва, 2-я Бауманская ул., д. 5, стр. 1 +7 (499) 263-60-45

press@bmstu.ru

http://baumanpress.ru 